\section{Nuevo presidente de la Academia Chilena de Medicina}

En Sesión Extraordinaria efectuada el miércoles $1^{\circ}$ de diciembre de 2011, el Dr. Rodolfo Armas Merino fue elegido Presidente de la Academia Chilena de Medicina para el período 2011-2013. El Dr. Armas sucede al Dr. Alejandro Goic G. quien condujo la institución durante la última década.

El Dr. Armas Merino es Profesor Titular de la Universidad de Chile, especialista en Medicina Interna y Gastroenterología. Además de su destacada trayectoria médica y académica y su extensa labor

\section{Congreso Chileno de Salud Pública}

\section{Chilean Congress of Public Health}

Se realizó en noviembre de 2010 en Santiago de Chile, con 600 asistentes. Fue organizado por la Escuela de Salud Pública de la Facultad de Medicina de la Universidad de Chile, en colaboración con el Ministerio de Salud, la Organización Panamericana de la Salud y Conicyt. El tema central fue "La salud pública en el Bicentenario: una agenda renovada ante el cambio de época". Se expusieron 350 trabajos de investigación. Las presentaciones estuvieron a cargo de investigadores, profesionales y estudiantes de Chile, México, Cuba, Brasil, Venezuela, Argentina y Alemania. Se abarcó más de una decena de áreas temáticas, destacando salud mental, globalización, salud de los trabajadores, métodos estadísticos, epidemiología, políticas y gestión de salud, medioambiente y otros.

Los resúmenes presentados fueron seleccionados por un comité con académicos de las Universidades Católica de Chile, de Tarapacá, de Antofagasta, de Valparaíso, de Santiago, Mayor, de La Frontera y de la Universidad de Chile. Se premió como mejor trabajo en la categoría de exposición oral a "Percepción del riesgo y beneficio sobre el cigarrillo y su relación con el tabaquismo adoles- docente y en investigación, ha tenido una activa y muy destacada participación en la dirección de importantes sociedades médicas científicas y en la fundación de nuevas y relevantes instituciones para el progreso de la medicina chilena, como son la Corporación Nacional Autónoma de Certificación de Especialidades Médicas (CONACEM), la Asociación de Sociedades Médicas Científicas (ASOCIMED) y el Fondo Nacional de Investigación en Salud (FONIS). El Dr. Rodolfo Armas Merino obtuvo el Premio Nacional de Medicina 2010, lo que se comentó en una Crónica de esta Revista, incluyendo su síntesis biográfica y una fotografía (Rev Med Chile 2010; 138: 784-5).

cente", de los autores Yerko Molina y Paula Repetto. En la categoría "posters" fue distinguido "Calidad bacteriológica de merluzas frescas comercializadas en el mercado fluvial de Valdivia", de autoría de Catherine Garay, Mónica Sáez y Rafael Tamayo.

La ceremonia inaugural fue encabezada por la Subsecretaria de Salud Pública, Dra. Liliana Jadue, acompañada por el Rector de la Universidad de Chile, Profesor Víctor Pérez, la Decana de la Facultad de Medicina, Dra. Cecilia Sepúlveda y el Director de la Escuela de Salud Pública y Presidente del Congreso, Dr. Giorgio Solimano. Hubo representantes del sector público y privado de salud y de las once instituciones que conformaron el Comité Científico.

La Subsecretaria de Salud Pública, Dra. Liliana Jadue, expresó que este congreso se plantea "como una nueva oportunidad de sumar esfuerzos y voluntades para continuar haciendo grande a nuestra salud pública, como lo fue ayer y lo sigue siendo hoy". Destacó que este evento "ya comienza a formar parte de la agenda país", valoró que se ponga el acento en la capacidad de realizar investigación organizada e independiente en salud pública, traspasando las capacidades del Estado y de las universidades en la generación de conocimiento e inteligencia aplicada en salud. Puntualizó que "Esto nos lleva a hacer un justo reconocimiento 
a quienes, muchas veces, deben realizar grandes esfuerzos para conseguir resultados modestos, pero con un gran potencial de aplicación".

El Presidente del Congreso, Dr. Giorgio Solimano, sostuvo que la Salud Pública en nuestro país es depositaria de una valiosa historia, que refuerza la necesidad de continuar trabajando por mejorar las condiciones de salud de la población, adaptándonos a una realidad social, cultural, económica y epidemiológica siempre cambiante. Este quehacer "sólo es concebible a través de la conjunción de esfuerzos entre quienes, desde las más diversas disciplinas y ámbitos de acción, tenemos mucho que aportar". Hizo un análisis crítico de la situación de la investigación en salud pública en el país, refiriéndose a las principales dificultades para su desarrollo. Mencionó los problemas de financiamiento, por escasez de recursos o por su orientación hacia otros tipos de investigación; los obstáculos para constituir equipos de investigación; la carencia de un sistema de registro y administración de la información e indicadores de salud accesible para los investigadores; problemas para conformar alianzas y vínculos entre distintos grupos y falta de tiempo para investigar. "A ello se suma una débil valoración social de la salud pública y cierta incomprensión de la importancia de la investigación en este campo por parte de los tomadores de decisión". Resaltó el aporte que programas como el Doctorado en Salud Pública, que dicta la Universidad de Chile, representan para la formación de investigadores de alto nivel en el país.

El Ministro de Salud, Dr. Jaime Mañalich, dio una charla sobre "Desarrollo y perspectiva de la salud en Chile: Los retos del bicentenario". Sostuvo que las reformas que ha emprendido nuestro país en los últimos años "han sobre tecnificado y sobre mecanizado el quehacer de la medicina. Tenemos que volver a la figura del esfuerzo sanitario público como bien de apropiación de todos y para eso necesitamos propuestas concretas". Destacó que se necesitan sugerencias de políticas efectivas "en el sentido de que conduzcan a resultados".

El Presidente de la Federación Mundial de Asociaciones de Salud Pública, Paulo Buss, habló sobre "Los desafíos para la salud pública contemporánea en tiempos de cambio". Defendió el rol del Estado como el principal actor institucional de la salud pública, señalando que bajo su liderazgo debiera estar el abordaje de los determinantes sociales.

El Presidente del Centro de Salud y Política Social de Estados Unidos, Stephen Isaacs, analizó la reforma sanitaria en ese país, calificándola "un paso importante, pero no suficiente”. Enumeró los intentos de distintos Presidentes estadounidenses por aumentar la cobertura de los seguros médicos y concluyó que "la estridente oposición a la reforma sanitaria obstaculizó todos los esfuerzos en pro de un cambio significativo y Estados Unidos siguió siendo el único país industrializado sin cobertura de seguro médico universal o casi universal".

Dr. Giorgio Solimano C. 